\title{
APROPRIAÇÃO CULTURAL ANTROPOFÁGICA E AS MÁSCARAS BRANCAS DO RACISMO INDIGESTO
}

\section{Charles Nunes Bahia}

\begin{abstract}
Mestre em Teoria do Direito pela Pontifícia Universidade Católica de Minas Gerais (2016). Bacharel em direito pela Pontifícia Universidade Católica de Minas Gerais (2012). Graduando em Filosofia pela Universidade Federal de Minas Gerais. Realizou pesquisa (graduação-sanduíche) na Faculdade de Direito da Universidade do Porto - Portugal (2011/2012). Email: charllones@hotmail.com
\end{abstract}

\section{RESUMO}

O presente artigo busca tecer um paralelo entre os ideais filosóficos de Oswald de Andrade e Franz Fanon. Para tanto, o conceito oswaldiano de antropofagia e a metaforização fanoniana das máscaras brancas em peles negras cruzar-se-ão num ponto de interseção marcado pelos meandros de uma apropriação cultural não antropofágica, pois geradora de um racismo indigesto.

PALAVRAS-CHAVE: Antropofagia. Apropriação Cultural. Máscaras Brancas. Racismo.

\section{ANTHROPOPHAGIC CULTURAL APPROPRIANTION AND WHITE MASKS OF INDIGESTIVE RACISM}

\begin{abstract}
This article seeks to draw a parallel between the philosophical ideals of Oswald de Andrade and Franz Fanon. To this end, the Oswaldian concept of anthropophagy and the fanonian metaphorization of white masks in black skins will intersect at an intersection point marked by the intricacies of a nonanthropophagic cultural appropriation, as it generates indigestible racism.
\end{abstract}

KEYWORDS: Anthropophagy. Cultural Appropriation. White Masks. Racism. 


\section{INTRODUÇÃO}

Num entremeio complexo de culturas fortemente marcadas pelo simbolismo resistente das mais diversas lutas por reconhecimento, desponta-se uma identidade brasileira fragmentária, devorada por processos de aculturação heterogêneos, paradoxalmente amalgamados por uma antropofagia cultural indigesta, assustadoramente lúdica, fabulosamente modernista. O começo do século XX voltava seus soslaios intelectuais ao modernismo à brasileira; esse estopim de ideais identitários cogentes, mas ao mesmo tempo salutares. Tupy or not Tupy. That is the question. De repente, tudo parecia incrivelmente digerível. Oswald de Andrade escrevia um autêntico manifesto antropofágico. Digeri-lo aprazivelmente era pressuposto para se fazer nascer uma cultura brasileiríssima.

Deglutir: apropriar-se do que não é nosso; criar uma cultura encharcada de brasilidade. Definição gramatical. Literatura. Filosofia. Um ponto de partida anacronicamente trazido ao presente a partir do resgate antropofágico da primeira ritualística canibal genuinamente brasileira, marcada pelo banquete de índios Caetés devoradores de um bispo em meados do ano 1556. Se no século XVI deglutia-se as partes humanas do epíscopo com o intuito de transferir para o corpo do devorador as boas características do devorado, na metafórica deglutição literário-filosófica de Oswald de Andrade, arquitetada nas idiossincrasias de um século XX forjado na vanguarda artística, deglutir-se-ia os fragmentos mais aprazíveis das várias culturas que se infiltraram na construção cultural do Brasil. O objetivo perfazia-se claríssimo: homogeneizar os fortes traços indígenas, europeus, africanos e norte-americanos em uma única identidade autenticamente brasileira.

Oswald de Andrade reivindicava a apropriação das culturas do colonizador e de todos aqueles que participaram ativamente na formação de uma identidade nacional. Para ele, as manifestações vindas de fora é que permitiam vislumbrar aqui dentro as formas mais primitivas da existência. Era como se o valor identitário se tramasse sobre uma Revolução Caraíba de culturas que, ao final, resultasse em uma conquista cultural única.

Uma apropriação cultural indigesta? Provavelmente. Basta olhar ao redor! Fez-se do apropriar um verbo imperativo às avessas. A tradição indígena, deglutida em manifestações singulares, assistiu suas memórias tornarem-se parte de um folclore jocoso. Os costumes negros, deglutidos pela indústria estética do capital, acompanharam seus símbolos da resistência transformarem-se em adornos vazios. Prevaleceu a cultura branca. Enquanto índios viram-se obrigados a se fechar no pouco que restava de sua cultura, os negros foram ainda mais coagidos. 
Passaram a usar máscaras brancas!

Este artigo não imerge no espectro indígena. Preferi desdobra-lo nos meandros do universo negro, onde o drama da apropriação cultural se mostra mais apavorante; onde dança-se um samba branco de origens negras periféricas; onde canta-se um axé esbranquiçado pelas elites baianas; onde o congado é rezado como manifestação da cultura cristã; onde veste-se o turbante como adorno do mundo europeizante da moda. Escolhi a indigestão antropofágica de uma país excessivamente racista. Para diagnosticar esse problema gástrico, contei com o auxílio de Frantz Fanon.

Por ter nascido na Martinica, em meio aos estigmas do racismo insofismável que imperava na Antilhas Caribenhas, Fanon se propôs a reescrever a história literário-filosófica da diáspora africana. Ao realizar críticas meticulosas e capilarizadas à negra e pequena burguesia antilhana, que preferiu embeber-se pelos hábitos europeus na tentativa de alcançar um embranquecimento social, acabou o escritor por escancarar uma apropriação cultural oportunista e etnocêntrica. Eram negros que se viam coagidos a mascarar a negritude ancestral que havia os moldado por séculos; negros que trajavam máscaras brancas; negros que acabavam por repetir determinados valores que foram primeiramente seus, mas que agora iam sendo apropriados por uma cultura branca que quis digeri-los da forma que julgou mais conveniente.

O fato é que existem valores que só se harmonizam com o meu molho. Nem sempre a apropriação cultural consegue resultados homogêneos. Significados de determinadas culturas costumam resistir. E porque resistem é que pretendo sobre essa resistência discorrer, tomando como base a realidade histórica brasileira. Ao colocar em salutar confronto os pensamentos de Oswald de Andrade e Frantz Fanon, perpassarei caminhos sinuosos da cultura popular brasileira; caminhos antropofágicos ainda indigestos, pois racistas por vocação hereditária.

\section{APROPRIAÇÃO CULTURAL ANTROPOFÁGICA}

A Semana da Arte Moderna de 1922, eternizada nas galerias artísticas paulistanas, deixou seu legado paradigmático a uma formação cultural ainda perdida em meio à europeização tupiniquim. O movimento antropofágico ali iniciado trouxe consigo, pela primeira vez, uma identidade brasileira modernista; moderna porque forjada numa brasilidade que não mais poderia ser europeia, nem indígena, tampouco negra, pois miscigenada pelos elementos culturais de todos esses povos. Entender esse fenômeno identitário pressupunha e ainda pressupõe a imersão na Antropofagia Filosófica de Oswald de Andrade, cuja proposta 
era assimilar outras culturas sem copia-las; realizar uma apropriação cultural salutar, digerindo tradições e regurgitando algo novo.

A concepção literário-filosófica de Oswald de Andrade sobre o fenômeno da apropriação cultural vai muito além dos limites da literatura ou da filosofia. O Manifesto Antropofágico (1928) perfaz-se como mecanismo avocado nos palcos políticos, econômicos e culturais; esses espaços públicos assimétricos onde são identificados os lados menos favorecidos em um mercado das trocas culturais (ROCHA, 2011). Isso porque se o Brasil escolheu devorar a cultura europeia, ruminando outra massa cultural, a Europa preferiu permanecer ditando regras e tradições. O Velho Mundo só não sabia que o Paraíso Tupiniquim absorveria esse conhecimento imposto de forma a transforma-lo em outro. De fato "nunca fomos catequizados. Vivemos através de um direito sonâmbulo. Fizemos Cristo nascer na Bahia. Ou em Belém do Pará” (ANDRADE, 1976).

A mimese, marcada pela repetição incansável de conceitos, não prosperou no Brasil Caraíba. O pai europeu, deglutido por inteiro, tinha nos seus pedaços as peças fundamentais para permitir ao devorador regurgitar um novo pai, alimentado por conceitos assimilados, mas nunca iguais. Era essa a transmutação oswaldiana do totem ao tabu; transmutação essa bem explicada por José Luís Jobim no seguinte trecho:

Depois de devorar o pai europeu, ao mesmo tempo odiado, temido, amado e admirado, criou-se o tabu (não matar o animal totêmico, substituto do pai europeu, exceto em ocasiões rituais). Ao colocar em xeque o tabu, abre-se a possibilidade de uma nova totemização, que não necessariamente colocará a "Criatura" europeia como figura paterna. A absorção do inimigo sacro, para transformá-lo em totem, proposta no Manifesto, não implica colocá-lo como pai (a lei, a norma, o poder), aceitando-o nos termos em que esse inimigo sacro se apresentou antes (JOBIM, 2015, P. 405).

Esse novo totem produzido não possui, portanto, a obrigação de repetir o papel do pai europeu; ele sequer precisa ser pai. Um novo devorar cria um outro totem que pode muito bem ser, segundo Oswald de Andrade, uma figura materna. Para o escritor paulistano, “o matriarcado tomba ante o voto de Minerva que absolve Orestes matricida. Com o matriarcado cai a propriedade comum do solo e inicia-se dialeticamente o 'progresso' - a propriedade privada, fortalecida desde então pelo direito paterno e pela herança" (ANDRADE, 1990, p. 122-123).

Oswald de Andrade se recusa a dar seguimento à figura paterna. O matriarcado vai 
muito mais além da conversão do totem em tabu. A figura da matriarca se volta à assunção de uma estrutura social dentro da qual não se sabia ao certo a identidade do pai, mas apenas da mãe. A sociedade do pater famílias, estruturada na propriedade privada, dá lugar à sociedade matriarcal, onde a propriedade é comum, pois destinada "à pacífica felicidade dos povos marginais, dos povos a-históricos, dos povos cuja finalidade não é mais do que viver sem se meterem a conquistadores, donos do mundo e fabricantes de impérios" (ANDRADE, 1978, p. 189).

Era a figura feminina, interiorizada como liderança no universo tribal, que parecia denotar as bases universalistas da igualdade. Apenas o índio e a mulher poderiam frear as mazelas desse capitalismo que pouco dá de comer; devorariam o todo, mas digeririam apenas a equidade necessária para realizar as mudanças necessárias ao Brasil. A intenção era mastigar os ricos para dar de comer aos pobres. Pelo menos é essa a metáfora que se pode extrair das palavras de Giuseppe Cocco, que faz uma releitura de Eduardo Viveiros de Castro, considerado um dos maiores estudiosos de Oswald de Andrade:

A antropofagia o que é? Tirar dos ricos. Entenda-se: 'vamos puxar da Europa o que nos interessa'. Vamos ser o outro em nossos próprio termos. Pegar a vanguarda europeia, trazer para cá, e dar para massas". Este é o sucesso da antropofagia, conclui Viveiros de Castro, depois de citar uma das grandes "fórmulas" de Oswald: "a massa ainda comerá o biscoito fino que fabrico" (COCCO, 2008, p. 21).

É nesse sentido, portanto, que se é permitido falar na antropofagia como condição necessária à igualdade. Sendo ela resistência e, ao mesmo tempo, autoafirmação de uma cultura marginalizada pelo colonialismo, não parece absurdo algum considera-la como "a única contribuição realmente anticolonialista que geramos" (CASTRO apud COCCO, 2008, p. 270). Mas em que sentido? Será que de fato esse devorar cultural conseguiu solapar a desigualdade? Ao que parece, "o Brasil soube manter uma muralha racista (branca) no caldeamento - a sopa da mestiçagem (COCCO, 2008, p. 287).

Oswald de Andrade sabia bem dos atrasos do Brasil; fomos os últimos a abolir uma escravidão que ainda hoje persiste, insiste, assombra. A antropofagia oswaldiana fez-se, portanto, promessa de igualdade: criou a utopia e tentou subverter a realidade. Os resultados poderiam ter sido gloriosos, mas o idealismo sucumbiu ao niilismo do real. A sopa da mestiçagem heterogênea continuou a ser servida. Jamais houve qualquer relação de alteridade na deglutição cultural africana. Nenhuma antropofagia foi anunciada como banquete da 
cultura dos escravos libertos. O historicismo trágico é testemunha viva de que, naquele momento pós-abolição, preferiu-se devorar a velha cultura europeia que surgia trazendo novas roupagens: o fluxo de imigrantes estrangeiros destinado a substituir a mão-de-obra escrava.

A cultura negra seguiu preterida, indigesta. $\mathrm{O}$ discurso sobre a mestiçagem fracassou ao tentar inserir a cultura africana nos alicerces da construção identitária brasileira. Por detrás de todo o racismo que foi segregando a cultura nacional, imperou um discurso mascarado pela tolerância; uma realidade falseada. Pareceu prevalecer a ideia de que nós poderíamos ser paradigmas da superação do preconceito de raças:

(...) a Alemanha racista precisa ser educada pelo nosso mulato, pelo chinês, pelo índio mais atrasado do Peru ou do México, pelo africano do Sudão. E precisa ser misturada de uma vez para sempre. Precisa ser desfeita no melting-pot do futuro. Ela precisa mulatizar-se (ANDRADE, 2004, p. 122, grifo nosso).

A passagem acima transcrita compõe uma entrevista concedida por Oswald de Andrade em meados 1945. Naquele tempo era quase consenso de que não havia racismo no Brasil. O racismo, no entanto, lá estava, velado, mascarado. Nosso mulato não poderia ter educado a Alemanha racista. Nosso mulato usava máscaras brancas. Mascara-lo com a branquitude era condição necessária para a tão almejada aceitação social. Ou se aceitava a cultura europeia ou não existiria espaço de autoafirmação na sociedade. Não havia antropofagia que fizesse a cultura brasileira digerir a ancestralidade africana. A regra não era outra senão esbranquiçar cada vez mais; ser um negro de alma branca.

Quando se pensou ser a vez das manifestações culturais negras, a antropofagia mostrou-se indigesta. Uma indigestão que não se deveu à obra filosófico-literária de Oswald de Andrade, mas à sua transmutação para uma realidade sectária e etnocêntrica. As máscaras brancas, colocadas em peles negras, impediram um devorar da cultura africana. Como consequência, houve um mascaramento cultural; um mascaramento que se mostra muito bem explicado pelo autor martinicano Frantz Fanon.

\section{MÁSCARAS BRANCAS}

Por que cargas d'água o negro se viu obrigado a trajar máscaras brancas? Para se sentir branco, ora! Não porque ele assim quis; escolher nunca chegou a ser verbo que lhe ofertasse transitividade. $O$ que havia era um fenômeno impositivo alimentado pelos 
desideratos de um imperativo colonialista que tinha no racismo a maior e mais poderosa engrenagem de fabricação de privilégios em extratos sociais alicerçados na desigualdade. Pelo menos é isso que pareceu afirmar, em meados do século XX, o pensador martinicano Frantz Fanon que, ao deixar sua terra natal nas Antilhas Caribenhas e passar pelo continente Africano, chegou finalmente à França, onde escreveria Pele Negra, Máscaras Brancas (1952), radiografia incontroversa de todas as sociedades racistas.

Frantz Fanon escreveu mais que um tratado; ele fez uma denúncia. Acreditar que existem diferentes níveis de racismo social é apenas algo que corrobora ainda mais aquelas manifestações racistas veladas; manifestações que se escondem, pelo menos na América Latina, sob o véu da mestiçagem legada por séculos de colonialismo. Nas palavras do autor martinicano:

(...) uma sociedade é racista ou não o é. Enquanto não compreendermos essa evidência, deixaremos de lado muitos problemas. Dizer, por exemplo, que o norte da França é mais racista do que o sul, que o racismo é obra de subalternos, o que, por conseguinte, não compromete de modo algum a elite, que a França é o país menos racista do mundo, é do feitio de homens incapazes de pensar corretamente (FANON, 2008, p. 85).

A exemplo da França, também o Brasil acreditou e ainda acredita na existência de um racismo brando por aqui. Aliás, o mundo latino acreditou em absurda falácia! Basta olhar ao nosso redor e constatar que os racistas latinos são tão perversos quanto os demais; eles também abraçaram o racismo como "mecanismo de exclusão social dos negros" (ROCHA, 2015, p. 114); eles também coagiram as peles negras ao uso das máscaras brancas.

O sistema colonial numa foi equânime. Uma vez livres da escravidão, os negros continuaram marginalizados, culturalmente apagados. Ou passavam por um processo de embranquecimento cultural ou desapareciam de vez. Apenas o negro que repetisse as tradições do colonizador encontraria um espaço na sociedade; um espaço mínimo dentro do qual jamais haveria uma equiparação ao branco. Prevalecia, pois, a inferioridade do colonizado; o combustível etnocêntrico necessário para fazer com que os próprios negros cressem que nunca possuíram uma cultura ou história. Para Gabriel dos Santos Rocha, a imposição da língua branca foi o grande catalisador desse agressivo processo de não equiparação étnica. Vejamos:

No contexto colonial, tanto nas Antilhas, quanto nos países africanos, Complexitas - Rev. Fil. Tem., Belém, v. 3, n. 2 , p. 40-53, jul./dec. 2018 - ISSN: 2525-4154 
o negro que detém a cultura do colonizador se eleva em seu grupo social, porém, nunca se equipara ao branco. A língua funciona como porta de entrada aos valores do colonizador transmitidos através da cultura: literatura, filosofia, conhecimento científico, onde são enaltecidos os feitos históricos, o progresso, as conquistas, em geral, exemplos que demarquem a pretensa superioridade do europeu sobre os outros povos justificando sua hegemonia perante o mundo (ROCHA, 2015, p. 115).

A língua atua, portanto, como mecanismo que protagoniza esse cenário colonizador onde se tira do negro toda sua valoração cultural ancestral. À margem desse estigma, vocifera Fanon em síntese ultrarrealista: "De um homem exige-se uma conduta de homem; de mim, uma conduta de homem negro. Eu acenava para o mundo e o mundo amputava meu entusiasmo. Exigiam que eu me confinasse, encolhesse" (2008, p.107).

O homem negro foi encolhendo; a cultura negra foi transformada em distopia. A tradição europeia infiltrou no cotidiano do negro de tal forma que ele somente acreditava numa ascensão social se ao menos se parecesse branco. Era preciso usar a máscara da branquitude e, nesse contexto, não havia nada mais branqueador que um casamento interracial. Uma vez casado(a) com o(a) parceiro(a) de pele branca, o(a) negro(a) passa a se antever não mais como negro(a), mas como pardo(a), moreno(a), quase branco(a). A esse processo de peseudoembranquecimento, Fanon atribui a seguinte descrição:

Da parte mais negra de minha alma, através da zona de meias-tintas, me vem este desejo repentino de ser branco. Não quero ser reconhecido como negro, e sim como branco. Ora — e nisto há um reconhecimento que Hegel não descreveu — quem pode proporcionálo, senão a branca? Amando-me ela me prova que sou digno de um amor branco. Sou amado como um branco. Sou um branco. Seu amor abre-me o ilustre corredor que conduz à plenitude. Esposo a cultura branca, a beleza branca, a brancura branca. Nestes seios brancos que minhas mãos onipresentes acariciam, é da civilização branca, da dignidade branca que me aproprio (FANON, 2008, p. 69).

A transcrição da passagem textual acima mostrou-se esboço indigesto de um quadro social com o qual Fanon não compactua. Não compactua porque pressupõe um mascaramento que culmina na reafirmação da inferioridade negra, na aceitação de um lugar de submissão onde o negro cada vez mais se aprisiona. Para o autor martinicano, "a inferiorização é o correlato nativo da superiorização europeia. Precisamos ter a coragem de dizer: é o racista que cria o inferiorizado" (FANON, 2008, p. 90).

As críticas de Fanon, no entanto, não se voltam diretamente ao negro que faz uso das 
máscaras brancas, mas ao sistema que os coage a usa-las. Para ele, essa possibilidade de escolha sobre mascarar-se ou não é antes ausência de possibilidade, já que há uma imposição que tolhe qualquer assunção consciente desse escolher. Nesse sentido:

(...) o negro não deve mais ser colocado diante deste dilema: branquear ou desaparecer, ele deve poder tomar consciência de uma nova possibilidade de existir; ou ainda, se a sociedade lhe cria dificuldades por causa de sua cor, se encontro em seus sonhos a expressão de um desejo inconsciente de mudar de cor, meu objetivo não será dissuadi-lo, aconselhando-o a 'manter as distâncias'; ao contrário, meu objetivo será, uma vez esclarecidas as causas, torna-lo capaz de escolher a ação (ou a passividade) a respeito da verdadeira origem do conflito, isto é, as estruturas sociais." (FANON, 2008, p. 96)

Fanon, portanto, acredita estar nas estruturas sociais o fundamento desse mascaramento da cultura negra. Sua orientação pelo materialismo histórico "considera que uma revolução não se faz através da cultura, mas através da transformação das condições materiais a partir das quais a cultura se torna possível (ROCHA, 2005, p. 111).

A descolonização parece ser o chamado de libertação vociferado por Fanon. Para alcança-la, no entanto, se mostra necessário desatar as antigas e resistentes amarras do capital; aquelas que impedem o resgate da cultura negra por aqueles que se viram coagidos ao branqueamento. Está-se diante, pois, de uma tarefa difícil; uma tarefa que na modernidade encontra obstáculos no próprio capitalismo que, do pedestal de sua sede hegemônica de poder, escolheu resgatar elementos da cultura negra e coloca-los à venda no mercado, destituindo-os do contexto histórico da representatividade ancestral que os dignifica. Ao realizar essa apropriação cultural indigesta, a antropofagia de Oswald de Andrade assiste ao descompasso entre literatura e realidade. No Brasil, as máscaras brancas permanecem colocadas, o racismo indigesto segue não ruminado e os engodos capitalistas continuam apropriando-se de elementos de matrizes africanas, tornando-os símbolos da branquitude colonial salutar.

\section{RACISMO INDIGESTO}

Uma sociedade colonial foi erguida no Brasil. Desde que os portugueses aqui aportaram, tudo o que se fez foi tentar repetir os valores culturais da "civilizada" metrópole. A impressão que a história nos passa é a de que já no primeiro contato com o colonizador as máscaras brancas foram distribuídas e implantadas nas faces dos colonizados. A partir daí, tudo o que se aprendeu com os indígenas tornou-se patrimônio intelectual branco. Mais tarde, Complexitas - Rev. Fil. Tem., Belém, v. 3, n. 2 , p. 40-53, jul./dec. 2018 - ISSN: 2525-4154 
com a chegada dos escravos, a sociedade assistiu ao combate daqueles valores culturais africanos que, de alguma forma, voltaram à cultura pátria como símbolo da branquitude da colônia. Até a tardia chegada do século XX, a sociedade brasileira jamais havia presenciado uma contingência reflexiva capaz de frear esse etnocentrismo tresloucado. Essa mudança de paradigma antropológico só ocorreu com a publicação do Manifesto Antropofágico de Oswald de Andrade.

Oswald de Andrade foi um marco para a sociedade brasileira; ele decidiu escrever sobre os valores culturais de um país que há poucos anos atrás ainda comercializava negros como escravos. Era o atraso do colonialismo que o incomodava; daí a ideia antropofágica de devorar outras culturas e reelabora-las segundo as idiossincrasias do povo brasileiro. Para João Cézar de Castro Rocha:

O gesto antropofágico é uma forma criativa de assimilação de conteúdos que, num primeiro momento, foram impostos. Sem mais nem menos: impostos. A antropofagia pretende transformar a natureza dessa relação através da assimilação volitiva de conteúdos selecionados: contra a imposição de dados, a volição no ato de devorálos (ROCHA, 2011, p. 666).

A antropofagia não se resume em uma repetição da cultura do colonizador para um linguajar brasileiro. É nesse sentido que o antropófago oswaldiano buscará escancarar, por meio da literatura, as ancestralidades várias de uma civilização tipicamente nossa; uma civilização cujos valores culturais foram obnubilados pelas imposições coloniais.

A aposta de Oswald de Andrade fez-se, portanto, genuína. Todavia, pecou por não conseguir encontrar uma correspondência com uma realidade brasileira composta por negros que continuaram trajando máscaras brancas. Se a escravidão puniu e privou as pessoas negras de manifestarem a sua cultura em solo tupiniquim, a abolição não permitiu que elas participassem ativamente da devoração. O racismo permaneceu indigesto!

Nesse cenário segregacionista, a cultura negra não digerida transformou-se em resistência; resistiu sob as vestes da negritude; a negritude que, segundo Munanga possui a seguinte origem:

A negritude nasce de um sentimento de frustração dos intelectuais negros por não terem encontrado no humanismo ocidental todas as dimensões de sua personalidade. Nesse sentido, é uma reação, uma defesa do perfil cultural do negro (...) uma recusa da assimilação colonial, uma rejeição política, um conjunto de valores do mundo 
negro, que devem ser reencontrados, defendidos e mesmo repensados. Resumindo, trata-se primeiro de proclamar a originalidade da organização sociocultural dos negros, para depois defender sua unidade através de uma política de contra-aculturação, ou seja, desalienação autêntica (MUNANGA apud ROCHA, 2015, p. 117).

A passagem transcrita é, pois, uma resposta ao racismo indigesto; definição clara de uma negritude que resiste ao embranquecimento das máscaras; uma negritude que busca resgatar laços culturais africanos originais, considerados aqueles carregados de uma valoração positiva. Pelas fortes mãos da resistência, resistem os quilombos, as tranças, a Umbanda, o Candomblé, o Maracatu, o Frevo, a Capoeira e tantos outros movimentos marginalizados pela branquitude hereditária.

Resistir é tarefa difícil, principalmente quando a resistência precisa lutar em espaços sectários e racistas. Muitas vezes acredita-se estar fazendo a revolução identitária quando, na verdade, se está apenas mantendo a valoração branca. É verdade, pois, que “de tempos em tempos ele (o preto) luta pela Liberdade e pela Justiça, mas se trata sempre de liberdade branca e de justiça branca, de valores secretados pelos senhores" (FANON, 2008, p.183). Destarte, não há deglutição antropofágica que consiga engolir a cultura negra da mesma forma que engole a cultura branca. Isso porque "a antropofagia também se refere a uma filiação, em que na carne do devorado está o gosto da família do devorador” (JOBIM, 2017).

$\mathrm{Na}$ luta por reconhecimento de uma negritude que nasce como autoafirmação cultural, valores ancestrais africanos buscam ser reconhecidos. Reconhecê-los, todavia, não é a intenção do branco. Apropriar-se dos mesmos e transforma-los em produto de mercado é o que a branquitude faz; e faz amparada pelo discurso de que está combatendo o racismo. Não há segredo: "o branco quer o mundo; ele o quer só para si. Ele se considera o senhor predestinado deste mundo. Ele o submete, estabelece-se entre ele e o mundo uma relação de apropriação" (FANON, 2008, p. 117).

O branco sempre quis o mundo. Com o auxílio "generoso" do capital, ele conseguiu até mesmo apropriar-se da cultura africana sem digeri-la; bastou transmuta-la em sua, adquirindo a posse, ignorando a graciosa e bem intencionada súplica faminta de Oswald de Andrade. Marchou-se a marcha da insensatez. Hoje, a produção massificada de objetos antes pertencentes ao entendimento das diversas identidades do povo africano ganha justificativas de cunho estético. A população negra tece críticas merecidas; afirma que esse desatino capitalista rouba a significação de elementos importantes para os que produziram aquela 
valoração cultural. Nada feito. O mundo pertence aos brancos!

O turbante, considerado alma mater da população negra, saiu de repente da marginalização às passarelas da moda. Apropriado e mal digerido, ele teve sua significação ancestral - atitude e fé - distorcida pelo capital. Nesse novo contexto, "a mulher branca que não faz parte de religiões de matriz africana usa o turbante, as tranças ou os dreads porque viu em revistas de moda que aquilo a deixa bela, porque encontrou locais onde poderia comprar tudo aquilo e sabe que receberá elogios com o uso" (JARDIM, 2017).

Esse apropriar-se que ignora o viés antropofágico ocorre, portanto, sempre que uma classe dominante desconsidera a valoração cultural de determinada etnia e faz de seus símbolos e práticas algo ultrajante sobre o ponto de vista social. Concomitantemente, “o mesmo grupo responsável pela marginalização passa, então, a ressignificar essas práticas e símbolos antes condenados, tentando torná-los atrativos para a maioria da população e visando o lucro" (JARDIM, 2017).

Não são poucos os exemplos dessa apropriação cultural capitalista. A maior exemplificação talvez seja o axé baiano, nascido das vozes negras do carnaval de Salvador, mas embranquecido pelos apropriadores culturais que hoje cobram absurdos para segregar, por imperativo do poder financeiro, os negros do lado de fora da corda que arrasta multidões nos trios elétricos. Nesse cenário, "se para um grupo existe uma história, uma questão identitária ou religiosa, o capital retira esse caráter único, transforma em mercadoria e disponibiliza para o consumo" (SOARES, 2017).

Há dúvidas de que o racismo à brasileira seja indigesto? Não bastou segregar as minorias negras; também se escolheu apropriar de elementos da cultura negra sem ao menos mastiga-los. Por sorte, "existem valores que só se harmonizam com o meu molho" (FANON, 2008, p. 117). Porque esses valores existem e conseguem se manter heterogêneos, a resistência se vê motivada a seguir em frente. O processo antropofágico não pode parar; deve vir acompanhado da descolonização. Esse descolonizar "que é criar homens novos, modificar fundamentalmente o ser, transformar espectadores em atores da história" (FANON, 2010, p. $52)$.

\section{CONSIDERAÇÕES FINAIS}

Fomos colonizados. Ainda somos colonizados. A história do Brasil vai deixando os rastros de um passado-presente injusto, pois racista por tradição. Nas esquinas, nas ruas, nos 
bares, o preconceito impera, vocifera o status quo, mas diz não ser racista. Era para antropofagia nos homogeneizar como brasileiros, cidadãos, humanos; apenas ela nos uniria. Oswald de Andrade criou a fórmula, o apetite, o digerir; criou a possibilidade de superarmos nosso passado colonial. Nada feito! Permanecemos submissos aos mandos e desmandos do colonizador. Não fomos descolonizados; nos mantivemos presos às amarras de um sistema que pouco dá de comer; que faz inimigos por corte e costura; que busca no capital a força necessária para continuar exercendo a salutar segregação que separa o globo terrestre em dois mundos distintos. Diante do espelho, nosso reflexo permanece mascarado; seríamos hipócritas se não víssemos as máscaras brancas que ditam as regras do jogo.

Frantz Fanon denunciou esse sistema onde o racismo está capilarizado. Negro, nascido em um território que havia sido colônia francesa, ele sabia bem da imposição colonial que ainda vigorava na Martinica; sabia também da bandeira racista existente na França, já que acompanhou de perto a hostilidade dos brancos no dia-a-dia de convivência com os negros. Para o autor martinicano, o cenário injusto que se abria aos seus olhos era claro: ou se usava uma máscara de branqueamento, agindo como se fosse um branco, ou não haveria espaço para a existência social. Não havia antropofagia que fosse capaz de fazer a digestão desse racismo. Da soma de tudo isso, sobrou apenas o resto. Mas o resto, ressignificado em resistência, também sucumbiu. De repente, o capitalismo, como bom aliado do branco que quer o mundo, fez dos símbolos dessa resistência produtos de mercado; proclamou a apropriação sem nunca ter engolido nada da cultura expropriada.

Oswald de Andrade e Frantz Fanon compartilhavam de um ponto de interseção ideológico: ambos queriam inaugurar um processo de descolonização; queriam criar seres humanos livres das amarras coloniais. $\mathrm{O}$ autor brasileiro parece ter fracassado justamente porque a sociedade brasileira não apenas segue suportando o racismo indigesto como também faz dele um instrumento do capital. Odeia-se os adereços negros até transforma-los em símbolos brancos da moda. Repudia-se as manifestações africanas até incorpora-las à tradição europeia; basta ver o congado. O que há é uma apropriação cultural às avessas, que não passa pelo processo digestivo oswaldiano e, por isso, acaba alvo das críticas do autor martinicano, que nos leva a refletir que esse processo antropofágico real não aconteceu porque os negros ainda seguem coagidos a usar máscaras brancas. 


\section{REFERÊNCIAS BIBLIOGRÁFICAS}

ANDRADE, Oswald de. A marcha das utopias. In: Do Pau-brasil à Antropofagia e às Utopias. Rio de Janeiro: Civilização Brasileira, 1978.

ANDRADE, Oswald de. $O$ manifesto antropófago. In: TELES, Gilberto Mendonça. Vanguarda europeia e modernismo brasileiro: apresentação e crítica dos principais manifestos vanguardistas. $3^{\mathrm{a}}$ ed. Petrópolis: Vozes, 1976.

ANDRADE, Oswald de. Os dentes do dragão. São Paulo: Ed. Globo, 1990.

ANDRADE, Oswald de. Ponta de Lança. São Paulo: Ed. Globo, 2004.

COCCO, Giuseppe. Antropofagias, racismo e ações afirmativas. In: Revista Eletrônica de Ciências Sociais. Ano 2, Volume 4, Agosto/2008.

FANON, Frantz. Os condenados da Terra. Minas Gerais: Editora UFJF, 2010.

FANON, Frantz. Pele negra, máscaras brancas. Salvador: Ed. UFBA, 2008.

JARDIM, Suzane. Entrevista à Carta Capital. In: $O$ uso de turbantes por pessoas brancas é apropriação cultural? Carta Capital, 18/02/2017. Disponível em: https://www.cartacapital.com.br/socieda de/turbantes-e-apropriacao-cultural

JOBIM, José Luís. Francesismo ou nacionalismo? Dilemas do modernismo brasileiro nas cartas dos anos 1920. In: Revista do Instituto de Estudos Brasileiros, $\mathrm{n}^{\circ}$ 68, 2017.

JOBIM, José Luís. O canibalismo como apropriação cultural: de Caliban ao Manifesto Antropófago. Gragoatá, v. 39, 2015.

ROCHA, Gabriel dos Santos. Antirracismo, negritude e universalismo em Pele negra, máscaras brancas de Frantz Fanon. In: Revista de História da África e de Estudos da Diáspora Africana. Ano VIII, $\mathrm{n}^{\mathrm{o}} \mathrm{XV}$, Agosto/2015.

ROCHA, João Cezar de Castro. Uma teoria de exportação? Ou: "Antropofagia como visão de mundo". In: Antropofagia hoje? São Paulo: É Realizações, 2011.

SOARES, Orson. Apresentação no Seminário Internacional sobre Colonialismo, Pensamento Descolonial e Direitos Humanos na América Latina. Unisinos. São Leopoldo, 2017.

BAHIA, C. N. Apropriação Cultural Antropofágica e as Máscaras Brancas do Racismo Indigesto. Complexitas - Rev. Fil. Tem. Belém, v. 3, n. 2, p. 40-53, jul./dec. 2018. Disponível em:< http://www.periodicos.ufpa.br/index.php/complexitas/article/view/6716>. Acesso em: 05 de agosto de 2019. 